\title{
Bladder Neurofibroma
}

National Cancer Institute

\section{Source}

National Cancer Institute. Bladder Neurofibroma. NCI Thesaurus. Code C159682.

A plexiform or diffuse neurofibroma arising from the bladder. 